\title{
'When the Numbers Stop Adding': Imagining Futures in Perilous Presents Among Youth in Nairobi Ghettos
}

\author{
Naomi van Stapele ${ }^{1}$ (D)
}

Accepted: 17 October 2020 / Published online: 1 December 2020

(C) The Author(s) 2020

\begin{abstract}
Studying the aspirations of young men, in Mathare, Nairobi, highlights their social becoming in contexts in which they incessantly risk social and physical death. Taking aspiration as a relational concept brings into view the temporal and spatial interactions between different aspirations and how these connect to emerging and future pathways of these young men. The ensuing relationalities at play are analysed through their context-bound negotiations of dominant gender norms to elucidate how these inform their social navigation towards male respectability, now and in the future. Adding the dimension of positionality here is useful to bring out how individual negotiations of gender norms in space and over time allows a nuanced view on situated entanglements of aspirations, pathways and dominant discourses and how these convolute and intensify in particular decision-making processes. The analyses are based on longitudinal ethnographic research with youth gangs in Nairobi for four months annually on average since 2005 .
\end{abstract}

Keywords Aspirations $\cdot$ Youth $\cdot$ Masculinity $\cdot$ Social navigation $\cdot$ Fear $\cdot$ Nairobi

\section{Resumé}

Etudier les aspirations des jeunes hommes à Mathare, Nairobi, met en évidence leur devenir sociale au sein d'un contexte dans lequel ils risquent incessamment la mort, socialement et physiquement. Prenant l' « aspiration » comme un concept relationnel met en vue les interactions temporelles et spatiales entre différents aspirations, et comment ces-ci sont connectés avec les trajets présents et futurs de ces jeunes hommes. Les relationalités qui en suivent sont analysées à travers la négociation des normes de genre, liés au contexte, pour élucider comment ces normes informent leur

Special Issue: Youth, Aspirations and the Life course: Development and the social production of aspirations in young lives.

Naomi van Stapele

vanstapele@iss.nl

1 Urban Governance and Development Policy, International Institute of Social Studies (ISS) at Erasmus University Rotterdam (EUR), Kortenaerkade 12, Den Haag 2518 AX, The Netherlands 
navigation sociale vers la respectabilité masculine, à présent et en futur. La dimension ajoutée de la positionalité permet de montrer comment les négociations individuelles des normes de genre, dans l'espace et dans le temps, permettent une vue nuancée sur les enchevêtrements situées des aspirations, des trajets, et des discours dominants, et comment ceux-ci convolutent et intensifient les processus décisionnels en particulier. Les analyses sont basées sur une recherche ethnographique longitudinale parmi des gangs de jeunes à Nairobi pendant quatre mois par an, en moyenne, depuis 2005.

\section{Introduction}

"To have a future is a decision, it is all about focus." Kingi, a middle-aged but young-looking man from the marginalised neighbourhood Mathare, Nairobi, and an ex-gang leader, looked piercingly at the youth present around him. The 15 young men were huddled together on wobbly benches, while Kingi sat on a yellow jerrycan in the middle, exposed to the blazing sun. Most of the youth were seated with stretched backs to catch the strip of shade from the iron sheet roof of the mud-walled bar, hand stretched above their heads to hold on to the wooden beam to stay balanced. The sun and dust were playing games with the wind, and every now and then a 'mini-tornado', as the men called it, whipped up some heated dust in their faces. The dialogue was organised by Kingi to discuss what he dubbed a 'change in mind-set'. Kingi had founded a community-based organisation in Mathare, a Nairobi ghetto, to help young men leave a life of crime and 'have a future', as he described it. In Nairobi's marginalised and highly policed neighbourhoods, locally labelled 'ghettos', gangs function as age-sets to provide a space for young men to acquire social, cultural and economic capital (Bourdieu 1986) to become providers for their families and friends (Van Stapele: forthcoming). The urgency of Kingi's work is underscored by the shocking fact that from the gang Kingi founded, at age 14, in 1992, only 6 out of the total 52 founding members were still alive in 2019 (Interview, 14 July 2019). Nearly half of the deceased members had been killed by police bullets, whereas others had succumbed to road accidents, alcohol or drug addiction or to the devastating consequences of neglected health problems like HIV infections and cancer. The majority of causes of their premature death derive from structural violence (such as police brutality, state neglect of roads and sewer systems in poor neighbourhoods and the corruption of government institutions) that affects the Kenyan urban poor in general, but which plays out differently for differently positioned people. For example, young urban poor men are at a much higher risk of being killed by police than their female counterparts (MSJC 2017). Most of Kingi's friends had died before reaching 25 . This age, 25 , had become a mythical number among young men in Mathare and other Nairobi ghettos. If one manages to overcome all hurdles and reach 25, they maintained, life would turn uphill from there.

At first glance, the language Kingi uses resonates with the dominant tenor of youth development programmes in African cities which often centres around notions 
of aspirations, capacity building and empowerment (see for instance the 'Crime $\mathrm{Si}$ Poa' ${ }^{1}$ intervention in Nairobi). Much has been written about the responsibilising, neoliberal tendencies of empowerment praxis in planned international development (Bracke 2016; Weidner 2009, see also Cornwall 2016). However, more attention is required to understand how youth in highly circumscribed, restricted contexts negotiate particular social norms and how this pertains to imagining temporal and spatial aspirations as part of their social navigation trajectories (Vigh 2006, 2009a, b). Not only will this help in unpacking and moving beyond the dominant planned development discourses and ensuing practices. In addition, it will be useful in revealing the situated and relational meanings young people ascribe to aspirations (or as Kingi said, 'having a focus' and 'deciding to have a future') and thus in interrogating how these pertain to individual pathways in volatile social, political and economic contexts.

Aspirations may reflect how much control people feel over their future (Bernard et al. 2008, p. 10), which accentuates that individual desires should not be considered in social isolation of feeling in control in relationship to other people, institutions and ideas. Given that aspirations are socially produced (Huijsmans et al., this issue), understanding how aspirations are contingently formed and change in space and over time requires a careful analysis of societies and cultures from individual perspectives. Aspirations as navigational capacities involve particular understandings of how one can navigate the "dense combination of nodes and pathways" (Appadurai 2004, p. 69) that lie between "the present and an imagined future" (Vigh 2006, p. 136, 2009a, b). Appadurai is not alone is his call for an "ethnography of the future", as it has been termed elsewhere (Clammer 2012, p. 129). The question how futures are imagined and negotiated and why becomes all the more urgent in contexts where many young men fear an early death. How does the potential loss of 'futurity' (Foti 2017) configure aspirations and decision-making in the now?

With this broader question in mind, I set out to study the imaginative practices of young men between 14-25 in Nairobi ghettos ${ }^{2}$ and highlight their social becoming in contexts in which they incessantly risk a premature death. This age-bracket has been chosen since most young men in Nairobi ghettos go through the rite of

\footnotetext{
1 https://www.crimesipoa.org/.

2 The material presented in this article is based on longitudinal ethnographic research with youth gangs in Nairobi ghettos since 2005. Prior to this, I was already involved in community-led organising by youth gangs in Nairobi. Since 1990, when I was 15 years old, I have spent four months annually on average working with young people in Mathare and other Nairobi ghettos on community-led action, which later developed into community-led research and action (CLRA). My long-term engagement has enabled me to build relationships of relative trust with many different groups in these neighbourhoods, such as young male gang members. The ideas and differences that Mathare residents would normally ascribe to my positionality as a wealthy and educated white women from The Netherlands were to some extent mitigated by the fact that I speak Sheng (a creolised urban language in East Africa derived from Swahili, English and other languages-Githiora 2018), live in a 'ghetto' when I am in Kenya and that many people have known me for years, even decades. However, trust is particularly fragile in these settings and I remain an outsider with access and privileges out of reach to most. Sometimes, my outsider position made the young men that feature here consider me as a sort of aunty they could confide in, though at other times I would be the first under suspicion when things turned bad. All the time, I walked on eggshells and constantly checked each action with a close circle of trusted friends from Mathare, like Kingi, who helped me to avoid making (too many) mistakes by always being radically honest with me.
} 
circumcision around 14 years old while many fear to die before reaching the age of 25. Cast as 'thugs' in Kenyan society, these young men are predominantly considered as 'deserving to die' (Kiama 2017). While facing such extreme forms of exclusion, dehumanisation and, ultimately, premature death, aspiring to 'have a future' becomes a political act. This future is mostly envisioned by them through the ideal of senior manhood which, as they described to me, can only be actualised by becoming a provider to one's extended family (which includes their parents and siblings, their own wife and children and also her parents and siblings). Most young men are expected and expect of themselves to achieve this around the age of thirty. However, this long-term aspiration is difficult to achieve for most which leads many to embark on various pathways in the hope one of them pans out. These pathways are also shaped by more immediate aspirations that are tied to their desire of achieving male respectability in the now. This points to the importance of understanding how these men move through (and are moved by-Vigh 2009a, b) circumscribed times and spaces and of how long and short-term aspirations are reconfigured accordingly (Frye 2012, p. 1573; Durham 2008). Taking aspiration as a relational concept brings into view the temporal and spatial interactions between different aspirations and how these connect to emerging and future pathways of these young men. The ensuing relationalities at play are analysed through their context-bound negotiations of dominant gender norms to elucidate how these inform their social navigation towards male respectability, now and in the future. Adding the dimension of positionality here is useful to bring out how individual negotiations of gender norms in space and over time allows an even more nuanced view on situated entanglements of aspirations, pathways and dominant discourses and how these convolute and intensify in particular decision-making processes.

Below, I focus on the case of one young man called Fake who tried to stop stealing while retaining a position in his gang and living up to expectations from his mother and later also from his girlfriend. Juggling multiple long- and short-term aspirations in perilous presents, Fake's story reveals some of the possibilities and limitations of aspirations in changing individual life courses.

\section{Leaving 'This Life' to Live}

The message read: 'A youth has died, you know him, it is Fake.' (15 August 2019). Shocked, I asked my friend Kingi, who had sent me the What's App message, if the police had killed him as they had done many of Fake's friends in recent years. Kenyan police are notorious for high levels of extrajudicial violence against crime and terror suspects (MSJC 2017; Jones et al. 2017; Osse 2016; Van Stapele 2016). It did not make sense, Fake was a 'reformed' man, as he had told me repeatedly and with which he had meant he was no longer involved in street muggings. Young people who are suspected of being engaged in street muggings are often killed by police in the latter's extremely brutal and criminal attempts to reduce crime in these neighbourhoods. Fake, it turned out, had been killed in a road accident, one of the other prominent causes of premature deaths among Nairobi's urban poor. 
I met Fake first in 2012 when he was 18 years old. At the time, he took part in gang dialogues organised by Ghetto Foundation, a community-led organisation working on gang violence in Mathare, which is almost always tied to political instigation. The dialogues took place during the protracted run-up to the much-anticipated General Elections (which eventually took place in March 2013) with the aim of preventing the mobilisation of gangs in politically motivated violence. These were the first elections organised after the post-election violence in 2007/8 which had left many parts of the country, including Mathare, in pieces (Musya et al. 2017). During that time, Fake had been a mere boy who had just dropped out of primary school because his single mother could no longer afford school fees. By 2012, Fake was a prominent member and designated future leader of a gang near the bridge that connected two parts of Mathare and which divided two antagonistic political strongholds. Gangs from both parts of Mathare had fought during the 2007/8 violence and rumours were rife that both sides were preparing for, what was widely dubbed, revenge attacks during the upcoming elections. These preparations, so the rumours went, entailed practicing in a forest nearby and stocking up on machetes. On all accounts, these were dangerous rumours because upon suspicion that one gang was preparing, the other would soon follow and perhaps even strike first. Mathare has had numerous flare ups of violence as a result of such rumours in the past (Bhavnani et al. 2009).

Kingi and his team from Ghetto Foundation arranged separate talks with gangs from both sides to prepare dialogues between them to quell such rumours and the potential for violence these carried. Fake had been absent during the initial talks, but he did attend the one before the upcoming dialogue between the two antagonistic groups. He entered the small plot of iron sheet houses midway through the meeting with his eyes fixed on me. He kept his eyes on me throughout as if he wanted to communicate something to me. Right after the talk, he briskly pulled me aside while most members gathered in clusters and were making jokes with the Ghetto Foundation staff to lighten up the charged atmosphere. In contrast to the majority of his fellow members, he wore a spotlessly clean outfit. Most of his peers worked at the riverside to complement their earnings by moonlighting as illegal alcohol distillers and they wore soot-stained overalls and gumboots. He told me: "You see them [other gang members], they work [referring to alcohol distilling], they steal, but it is never enough. I don't want this life anymore. It is risky, so many of us have been killed. I want to do the interview for [the computer class]." At the time, Ghetto Foundation collaborated with an NGO to provide young people in underserviced neighbourhoods like Mathare with high quality ICT-trainings and internships.

Fake declared to me that he had made a decision. The focus on decisionmaking may bring to mind a rational actor, an agent with full view of the power configurations in which he is positioned. Yet, most people (if not all) are not autonomous and rational actors, but make decisions without full awareness, out of impulse and routine, based on desires, and by following the examples of others. Intentionality denotes actively motivated actions, and includes "all the ways in which action is cognitively and emotionally pointed towards some purpose" (Ortner 2006, p. 134). Fake did have a purpose. He intended to live so he could become a provider to his family. In the context of close to $100 \%$ formal 
unemployment in his part of the 'ghetto' and very few opportunities for informal work and business (legal and otherwise), he had followed a path common to most young men in Mathare; a path of illegality and criminality. His decision to leave 'this life' was mostly informed by the fear of being killed by police. He aspired to grow old. Fake jutted his chin in the direction of his peers: "They are 'don't care', they live for today, and they don't expect to grow old. They will be killed, maybe tomorrow. You heard Mwas, huh? When he said next meeting one of us will not be here." This turned out to be a chilling prediction seeing that before the next meeting a few weeks later Mwas himself had been decapitated by a group of female neighbours with a machete, in a spur of immediate punishment, because they suspected him of stealing a mobile phone from one of them. Fake's description of his peers as 'don't care' was a common phrase in Mathare which alluded to a dominant modality with which (mostly) young men attempted to present an impervious demeanour (Majors and Billson 1993). Fake himself mastered this 'cool pose' exceptionally well but he no longer wanted to ascribe to the risk behaviours that were often associated with this attitude, such as mugging people and using various types of drugs. Many of his friends often went out at night to 'add numbers' as mugging people or robbing houses in nearby neighbourhoods is often euphemistically called in popular language. The phrase 'adding numbers' refers to the way such jobs are often arranged within the gang, which often entails an inventory of willing 'numbers' to go for a particular job. In the case a team falls short of members they would ask a wider circle of friends to 'add a number' and join them. The phrase has also caught on as a way to talk about stealing in code, which is a familiar linguistic strategy for covert practices within social spaces marked by high levels of (state) scrutiny (Githinji 2006).

A friend of Fake and fellow gang member later explained to me while hanging out in the evening after the dialogue had taken place: "We often say, why not? Eh? Why not steal? Add a number. I don't want to do backbreaking work, not earning anything, just to die of disease before I grow old. We need to live now, get money quick, have fun now then we die. At least we have fun, something our parents never had.". His words echoed a common adage among the gang members: "Better live today than die tomorrow." The multiple meanings of this axiom point at a tendency to enjoy the moment while it lasts, but it also comments on the struggle of some of their parents who had worked hard and then died, without having actually lived. Against the backdrop of quick and slow death, everyday violence and hardly any ways to earn money outside dangerous forms illegality and criminality, Fake's decision that he wanted to change his life around to have a future was a big step for him, as he put it, and he needed my help. He explained that he could not talk to Kingi or his male friends. He could not ask for help from another man in his neighbourhood or family circle for this would entail showing weakness to his fellow men and fracture his cool pose and erode his carefully curated reputation and social status. Kingi later affirmed that it is difficult for most men in Mathare to trust each other and confide in one another: "Eeeeeh. You need to show you can do it by yourself, you can't trust anyone, you can only trust yourself." I asked Kingi during the evening why he thought Fake had approached me, he said: "Fake knows you from when he was a boy, hahaha 
all of them do. But you are also a white person, from outside, you are not their family or neighbour, like we all are so they can tell you things we can't tell each other." This help he asked for turned out to be frequent talks with him over lunch and tea. During these conversations, he constantly imagined and modified different trajectories towards various futures in his head, meticulously discussing each possible step along the way with me while asking my advice.

Fake aspired to a different life than what he was accustomed to and what he experienced as a lived reality for young men like him. He asked my advice, he clarified, because "you are from outside and know things from outside." He wanted to familiarise himself with possibilities outside his frame of reference. Our frequent conversations over the years turned out to be free flowing talks in which Fake took the lead. He generally would start off our meetings with a current issue that bothered him, and I would urge him on by asking questions and listening deeply. I refrained from giving him direct advice even when he asked, given that I did not feel best placed to give advice about a life I never lived. Instead, I tried to be a sounding board and encouraged him more than anything else to make his own decisions. He shared with me that my non-judgemental listening, sometimes for hours on end, and my often very naïve questions prompted him to explore his aspirations more profoundly and opened his mind to new possibilities.

Aspirations, preferences, expectations and beliefs about our abilities reflect earlier experiences and decisions as much as they shape future ones. Ray understands aspirations as "the social grounding of individual desires" (Ray 2006, p. 409), which are inherently relational. Individual desires, preferences and behaviour are not determined in isolation but influenced by social environments and interactions, for instance by discursively informed expectations people have towards one another. Aspirations "are inevitably tied up with more general norms, presumptions, and axioms about the good life, and life more generally" (Appadurai 2004, p. 68). Particular aspirations are innately multidimensional, multifaceted and socially embedded (Appadurai 2004; Camfield and Copestake 2010). As such, aspirations are bound up with ideas on 'a good life' and can thus be considered as situated vistas onto the future (ends) as well as moral compasses for action in the present moment (means), which reveals the co-constitutive nature of 'ends' and 'means' and the potentiality of temporal shifts and even conflation between them (Frye 2012, p. 1572).

Fake was deeply torn between his more long-term aspiration of achieving senior manhood and his short-term aspirations of gaining respect in the now. He shared: "When I buy my mother groceries, I become an important person to her, she respects me, now!" To buy his mother groceries he needed money, which he, in his view, could only earn through illegal means together with his fellow gang members. Joining his friends to earn money together also gained their respect in the moment. However, this also meant jeopardising his life and therefore his chance of having a future in the most literal sense of the word. He constantly contemplated different definitions of 'a good life' for a young man in a Nairobi ghetto and what would gain him respect from peers, family and neighbours, now and later. His main conundrum was that the ultimate aspiration of becoming a senior provider could be achieved through different pathways, but each trajectory that 
Fake imagined denoted unfathomable risks while also potentially negating other more immediate aspirations such as being respected by his peers or his mother.

\section{Between Desires and Decisions}

Fake's aspiration to leave stealing (but not the gang) derived from a desire for a safer life in the present and to increase the odds of having a future. Fake had lost many friends, including his older brother, in his young life. Between the time we met in 2012 and his death in 2019, he lost his cousin, four of his close friends and fellow gang members and two of his neighbours to police bullets. He also lost many more friends to road accidents and neglected health problems. The loss of so many of his peers made the tensions between his different long and short ambitions all the more acute and insoluble. All his ambitions were inscribed by the various social positions he embodied as a prominent gang member and designated future gang leader, a son to his mother, a brother to his sisters, etc. Each position bestowed different social expectations on him, most of which he affirmed and tried to adhere to. Hence, moving through different social spaces also moved his positioning, which became visible through the way he negotiated dominant social norms and expectations bestowed on him in a particular space (such as at home and at the gang hang-out). However, not only space, also time and specific life events that happened over time shaped how he positioned himself by negotiating social norms, as Fake over time shifted his negotiation of ideal notions of manhood, as will become clearer below.

By negotiation I mean how people who, in particular contexts are not part of powerful institutions, relate to, respond to, comply with and contest widely accepted and highly authoritative 'truths'. Through the process of negotiation, men like Fake position themselves within the dominant discursive frameworks that impose subjectivities on them. My aim is to grasp the agency of the young men like Fake in Mathare by analysing their narrations of the self, for it is the act of narration (Butler 1997; Davids and Willemse 2014, p. 3; Rodan and Huijsmans, this issue) in its broadest sense that constitutes, and is constituted by, the process of negotiation. Discourse (Mills 2006, pp. 77-102) offers possible positions for subjects to adopt or not (Willemse 2007, p. 128). People are agents of their own positioning, but do not have the same space within discourse to negotiate dominant norms, imagine alternative positions and enact agency (Willemse 2007, pp. 45/132; Skeggs 2004).

Looking at how Fake imagined aspirations and negotiated social norms tied to manhood through his positioning in particular social spaces and over time contributes an important analytical dimension to the concept of 'social navigation', as developed by Vigh (e.g. 2006, 2009a, b). Social navigation is useful to study decision-making among men like Fake and analyse their movements (including making decisions and acting on them) within constantly shifting temporal and spatial contexts. This notion highlights the social and bodily praxis aimed at improving social possibilities by evaluating "the immediate and the imagined" (Vigh 2006, pp. 13/136) and taking action (including 'inaction') accordingly. It 
is particularly appropriate to study the experiential level of struggling to obtain social status within highly unstable contexts and to underline the interactivity of practice and the (social, political, economic) environment, from the vantage point of a young gang member. Men like Fake are embedded in and move through multiple social relationships and power configurations (Ortner 2006; Mills 2006) that are marked by certain uncertainty (Vigh 2009a, b; Whyte 1997):

The concept, in other words, highlights motion within motion; it is the act of moving in environment that is wavering and unsettled, and when used to illuminate social life it directs our attention to the fact that we move in social environments of actors and actants, individuals and institutions, that engage and move us as we move along. As such, the concept adds a third dimension to our understanding of movement and mobility. Where we normally look either at the way social formations move and change over time, or the way agents move within social formations, navigation allows us to see the intersection-or rather interactivity (cf. Jensen 1998) between the two.[Vigh 2009b, p. 420].

Hence, social navigation entails constant reorientation in response to evolving contexts and events and shifting power relations, but always within the context of circumscribed pathways. By connecting the theory of social navigation to exploring the ways in which men like Fake negotiate social norms such as (senior) male providership in space and over time offers an even deeper insight into their everyday actions. In this case, it helps to elucidate the way in which Fake's commitment to particular masculine ideals (both in the long- and in the short-term) informed not only his context bound aspirations but also his dilemmas and how these governed his decision-making in the everyday. His imagined pathways were not intentional, single or linear routes that were obvious in direction and had clearly defined destinations, but unfolding, multiple, ambiguous and diverging imaginings without fixed outcomes. His decision-making varied from daily decisions about work (including about 'adding numbers' or not) to deciding to marry his girlfriend or not. His movements in, and evaluations of, the immediate and the imagined were informed by his deep-seated anxieties about his present-day social status, about his desired future and about unfolding im/possibilities. All these affects and desires were constantly contemplated, adapted and reconstructed by him, as were the multiple pathways to realising them. The metaphor used by Vigh to describe social navigation, namely as the ship that sails through dark and unpredictable waters towards still invisible, and thus imagined, and shifting horizons, aptly fits the deep uncertainty that marked Fake's daily deliberations and everyday life. Moved by high waters, rough winds and dangerous storms, he navigated social relationships in the moment, with the main aim being to achieve senior providership. As such, bringing his situated negotiations of social norms in view together with the concept of social navigation helps to clarify how gendered societal expectations have an impact on men like Fake, and the way emerging opportunities and constraints shape their possible orientations into the future and decision-making in the present moment.

Fake continuously affirmed his desire to achieve senior male providership with fervour. During one of our lunches in 2012 he said: "It is the sole purpose for a man to provide for his family. I am a man, so I need to take care of my mother and sisters. 
I don't have a father, so I am the man to them now my brother is dead." Fake often stopped smiling when he spoke of his responsibilities as a man. At 18, he expressed both pride and anxiety over his role as provider, but he never wavered in his conviction that this is what he aspired to, thus affirming this particular masculine norm. At the same time, Fake's aspiration to have a future and grow into a position of senior male providership for his extended family at the age of thirty stood on tense footing with his desire to provide for his mother and sister in the now and become a gang leader in the near future and gain respect from his peers. Living a safer life had direct implications for the present moment for it would instantly diminish his income and therefore also reduce his position with regard to his mother and sister. Moreover, it would also risk his status in the group, seeing that he would not be able to join his members to go clubbing - a common practice to forge brotherhood among the members. Fake was widely regarded by his fellow gang members as a promising future gang leader despite his young age. When I met him, he had already established a large network of brokers in Eastlands in Nairobi where Mathare is located. 'Broker' is a local term, uttered in English, which in this context denotes intermediaries who help young gang members in accessing legal, illegal and criminal work opportunities, and they may vary from brokers in stolen goods, drugs and other illegal goods to brokers for politicians, government officials and NGOs (which for gangs mostly entails work as security providers at events). Fake's brother had helped him connect to a few influential brokers before he was killed by police. After his death, Fake inherited his brother's contacts and soon discovered that he excelled in this type of networking. On one hand the gang seemed to hinder some of his longterm ambitions. On the other hand, it was also the locus of his other more short-term ambitions and to some extent also potentially allowed him to work towards achieving his ultimate aspiration of independent providership for it enabled him to make some money to already provide for his mother in the present moment.

In contrast to dominant views, gangs in Mathare allow young men like Fake to earn money to provide for their direct families and as such they are locally recognised as a suitable social space for young men, all the more so because it is attached to a particular local practice in Mathare and several other ghettos in Nairobi that is considered crucial in the process of becoming (senior) men. Young men in these neighbourhoods generally move out of their family homes after circumcision, which mostly takes place around the age of 14 . As soon as they are circumcised, these youth are commonly considered 'junior men' and from then onwards have to take care of themselves while gradually taking up responsibilities to provide for their family, especially their mother, sisters and (when married) also for their wives and her family (van Stapele forthcoming). Therefore, eventually being able to leave the gang is part of gang membership for the main purpose of the gang is to provide these men with the support structures as they graduate from junior to senior men. This gradual process is observed by growing social and economic independence from the gang. This central feature of gang membership in Mathare deviates from common understandings of gangs (Brotherton 2019). The gang space as an age-set guides young men to eventually become independent from the gang. Hence, leaving the gang is a big step towards attaining male respectability and towards achieving senior manhood. Independence denoted becoming a provider for extended family and 
a growing circle of friends based on autonomous sources of income, which could vary from having a micro-business - like a shop or a butchery-to becoming a boss in the alcohol or heroin trade. Alcohol or heroin bosses are generally not regarded as part of the gang, but are usually older men and women who hire a particular gang for work and often have long-standing agreements to work with particular groups.

Considering the function of the gang space in helping young men in becoming independent senior providers, Fake's desire to stop 'adding numbers' was not unique, even if only few succeeded in leaving 'this life'. I asked some of his friends and discussed this also with many other gang members in other neighbourhoods, and most of these men wanted to find opportunities outside crime (i.e. street muggings and house robberies) but often lacked focus, as one of them shared during an evening chat at their hang-out in September 2013: "It is hard to stay focussed, so many demands. It is easy to go back to stealing, quick money, then you think risks are everywhere or you get angry, why is life like this for me? And you steal, you lose focus, then you die." What stood out was Fake's ability to stay focussed and think of tomorrow in perilous presents while surviving in the everyday. The English term focus is often used in local Sheng to describe a mental state of looking ahead and have faith in a better tomorrow. Some of the men described it as having a picture of themselves in their head as independent providers and fathers that guided their everyday decision-making. Fake's focus on becoming a provider was no mean feat, especially considering his young age, and reveals that such decisionmaking is in fact an everyday process of staying the course despite unpredictable waters. As a consequence, at the time of the interview with the ICT training course he was calibrating different short- and long-term aspirations at once, varying in degree of importance to him, that potentially reinforced, contracted or collapsed into one another. The long-term aspiration to become a senior provider for his extended family depended on him having a future. Meanwhile, his short-term desire to gain respect and grow into a position of leadership in the gang partly depended on his financial contribution to having fun together at clubs which due to lack of other means he could only acquire through stealing. Stealing also offered him money in the short-term to provide for his mother and sisters, as he was expected to, but this was not a long-term solution. His focus on a (better) tomorrow, or, as Kingi said at the beginning of this article, his decision to 'have a future', thus indicated various pathways that could potentially cancel each other out, and going for the interview to enrol in the ICT course was not an apparent or immediate solution to his conundrum, as the next section explores.

\section{Fear of Unfamiliar Futures}

After various lunch meetings, Fake concluded that there were two main pathways that stretched out before him: (a) becoming the group leader as soon as possible or (b) join the ICT course and work in the city. Both pathways were riddled with immediate life-and-death risks. Obviously, moving up in the gang hierarchy would not only be met with resistance from the current leader but would also increase police attention. Yet, investing in the computer course also involved extreme risks because 
of a diminishing income accompanied with a rise in living costs (for transport and lunch during his internship). He had already shared with me that he was ready to walk and go hungry during the day, and he worried incessantly about the lack of funds he would have to help his mother pay rent and school fees for his sisters, as his mother expected of him. Moreover, the ICT course would entail frequent movement outside the gang space which would instantly make him vulnerable to police violence given that he had already been marked by the local 'killer cops' as a 'thug'. Kingi exclaimed during an interview in January 2017: "Killer cops, huh, they see you as a thug, you can't change, when you are on the list you die, period. As much as we try to reform our youth, the cops don't see that and they keep on killing them." Fake relayed to me right before the interview that he finally opted to combine both pathways thinking they could reinforce one another. He would occasionally 'add numbers' at night to survive and try retain his position in the group and help his mother out while also attending the ICT course during the day. This would allow him to maintain a position of respect in his mother's house and in the gang while also working towards his aspiration of becoming independent of the gang and actualising the position of senior providership. He had evaluated the risks, he said, and stated emphatically that this was the only way out, that is until he arrived at the interview.

On the day of the interview I rang him and wished him good luck, he sounded confident and eager. However, later that day, Kingi phoned me. He sounded devastated. "Fake did not make it to the interview." I gasped. He continued: "I think he saw all these youth from Eastleigh, Huruma [slightly wealthier neighbourhoods near Mathare], and he left." When we met again, a year later in August 2013, Fake told me that he had looked at these youth with their polished shoes and Sheng and did not feel as if he belonged. He thought he would never pass the interview as a 'ghetto boy', as he termed himself during that conversation. Out of sheer frustration he had quickly cut the corner near the Ghetto Foundation office and stolen a phone from a woman near the bus stop. Instantly, the woman had started screaming, gathering a crowd that had beaten him so ferociously that he ended up in ICU for 6 months. He shared: "I was so angry, why don't I have that life, of mama boys, living in a stone house. Drinking tea with milk." The scars were still visible on his handsome face, but by an unbelievable strike of luck his teeth were still intact. "I knew I did not belong when I saw them. I did not even finish primary school." The computer course, even if located near his house, had been dominated by youth from outside his neighbourhood and they had confronted him with how society casts him as a 'thug'. He explained: "it was too many new things, going to school, computers, so many youths from outside ghetto, I felt like nothing, a dirty ghetto boy, a thug." The threat of being stereotyped (Spencer et al. 2016) and faced with the utter unfamiliarity of this new life and the apparent ease and entitlement of the other applicants, he had felt frightened and angry to the extent that he, as he shared with me, had vented his frustration in an act that affirmed the very subject position he aimed to escape, namely that of the 'thug'. This reveals that when studying aspirations as a relational concept it is not only important to take into account the interaction with other aspirations, also in terms of their temporality and spatiality as discussed above. It is also crucial to explore the way pathways and ensuing actions intersect in the present and 
potentially thwart future pathways and the actualisation of long-term aspirations. Above all, it is elucidating to look at how all this hinges on context-bound negotiations of pertinent subject positions that are, in this case, tied to particular gender norms and concomitant subjectivities (such as 'junior/senior man', 'thug' and 'ghetto boy').

During our conversation in 2013, Fake shared that the time in hospital had changed him. "I don't want to live this life, none of us do, living scared, constantly expecting pain, death. You get a few shillings, but you lose your peace, ... and your future!" The change in behaviour following his period in hospital had been informed mostly by fear. Fear made him more focussed than ever before. Even before his sickbed, he had aspired to change his life around and develop a livelihood outside the gang, but now, he said, "I became more open to other work, to do odd jobs, and not always want quick money." For a few years, Fake continued to steal occasionally but he also took up all kinds of daily work in the neighbourhood. Sometimes I met him in dirty overalls cutting firewood for the distillery near the river, or while carrying goods up the road for a shopkeeper. His reputation changed in the area. He still held his swag high, as he dubbed it, and continued to demand respect from peers because of his connections to a few local political and businesspeople, but he seemed less invested in becoming a gang leader. In fact, he started to operate more and more like a broker for the gang, which was a bit of an outsider position for it meant he also sometimes worked with other groups. Through his daily work, he established contacts with market women and a few local business owners who previously had cast him off as a 'thug'. Some of the residents in his area told me that they started to see him as 'hard working', often a descriptor which was locally juxtaposed to the thug imaginary (van Stapele forthcoming), and he took part in a neighbourhood security group. He laughed proudly when we discussed this: "Yes, I am not that small boy anymore, that thug, I give back to my community now by protecting it."

At 21, he married his girlfriend who had already given birth to a baby boy two years before, which added to his responsibilities as a provider. "Mini-me, he is." He laughed. "We are all teen fathers in this hood, we fear to die at 25 , so you leave your mark." He recounted when his friend Sojaa had turned 25 the other day, they had thrown him a party, not for his birthday, as Fake explicated, but because he had become 'a grandfather', an 'elder'. His voice turned soft: "I also want to become a grandfather, that is why I changed my life." At that moment, it was unclear to me if he talked about reaching the age of 25 himself or seeing his own son grow old enough to have children himself. He emphasised that this time his change was permanent, "not like when I went to the interview." Driven by this desire to stay alive and become the senior provider also to his young family and in-laws, Fake increasingly avoided the temptation to 'add numbers', but gradually earned his money through less risky ways, which was a painstaking endeavour of staying the course, as he recounted to me, because it entailed less earnings and much, much more effort. He persevered, he told me, because the respect this earned him among local shopkeepers, market women and other small business owners compensated for the dip in his income. During an interview in February 2016 he told me: "Haha, I did not know but this respect is important to me, how they see me, not like before." He 
maintained his prominent membership position in the gang, even if slightly outside, because of the work opportunities he could offer through his connections outside the group. However, he had long given up his previous ambition to become the group's leader. Early 2017, one of the local shopkeepers he occasionally had worked for hired him to drive his motorcycle taxi for him. For two years, Fake worked 6 days a week, finally earning enough money to move his young family into a stone house, another aspiration coming true. In April 2019, his $25^{\text {th }}$ birthday came and went. Not many knew his age, so his peers did not throw him a party, but he knew that he had passed the magical age of 25 and that he too had become a 'grandfather'. He marked it by sending me and Kingi a message on his 'achievement'.

After receiving the What's App message on 15 August 2019, I talked to Kingi on the phone to learn more about Fake's death. Fake had been hit by a lorry on the highway near Mathare while driving the motorcycle taxi. He had been killed instantly. We talked for long. The bitter irony did not escape us while talking on the phone: He had only just turned 25.

\section{Concluding Remarks}

Starting from the narratives of interlocutors such as Fake reveals aspiration as a relational concept in myriad ways. Highlighted by his words and life story are the way aspirations depend on dominant norms and how these are negotiated by people and on the interaction of particular aspirations with other temporal and spatial aspirations and, perhaps even more so, with the multiple pathways that are mapped and enacted (through decision-making and other actions) in their quests to actualise these context-bound aspirations. Fake's most prominent long-term aspiration was to become a senior provider, informed by the masculine norm in Kenya which inscribes men as providers from the age of adulthood, often marked by circumcision. These junior men are not expected to fully provide for their extended family directly, but they should gradually take on a growing burden of such responsibilities and are expected to actualise the position of senior manhood around the age of thirty. This ideal was affirmed by Fake and guided his everyday decision-making as well as shape many of his other long- and short-term aspirations, thus pointing at the entanglement of aspirations, discursive configurations and ensuing subjectivities.

Looking at the way in which Fake negotiated the gender norms at different moments and spaces in his short life and how this shaped and shifted his investment in long- and short-term aspirations (and thus his enactments of various pathways) added to the notion of social navigation for it allowed an even more nuanced view on why he made particular decisions. The experience of police brutality and the loss of his brother, friends and neighbours to police violence led Fake to reconsider the risks he took by 'adding numbers' on a daily basis. Perhaps individual resources such as his connections to brokers or the validation he experienced from peers as the designated future leader of the gang allowed him to consider new options, such as the ICT course. The fact that he aspired to a future, a tomorrow, which would allow him to work towards senior providership, denoted that he had to change his decisions in the present moment which would have immediate negative effects on 
his standing in the group, or so he feared. Accordingly, aspirations tie in with each other and are simultaneously reconfigured through positionality, which indicates that orientations into the future not only emerge from what is discursively unfolding as possible horizons within shifting structural forces but also from the agentive act of positioning in turbulent 'every-days'. This becomes detectable by zooming in on the way agents negotiate dominant norms and position themselves accordingly while navigating daily life and imagining ever-changing futures.

To men like Fake, the local notion of focus was a deliberate device inspired by an aspiration (in this case of senior manhood) to guide their decision-making in the volatility of the present moment. Personal characteristics also play an important role. Indeed, Fake was unique among his peers in his bold commitment to staying focussed, but it is possible to state that in a more general sense having a focus was popularly considered a life-line. However, holding on to this line was difficult for most in face of extreme pressures and temporal loss of faith in individual ability and structural possibility to ever achieve a particular circumscribed aspiration.

At first, Fake seemed steady in his grip while plotting in detail how the ICT course could translate to a pathway out of 'crime' and move him closer towards a position of male respectability. He resisted being positioned as a 'thug', a mere 'ghetto boy', yet at the moment of the interview he was confronted with the threat of being stereotyped as such, which swayed his positioning in an instant and his resistance turned into affirmation-almost to his own detriment. Society expected from him providership but also casted him as a 'thug'. This brings to light how societal norms and stereotypes may interact with self-image and shape and interrupt individual aspirations. Fake seemingly managed to fight his own dehumanisation in society and aspire to have a future until he was faced with his own self-doubt and internalised stereotyping which made him change the way he negotiated the dominant discourse, even if momentarily. Right away, his decisions and actions changed in the present with almost lethal repercussions.

His near-death experience and long hospitalisation urged Fake to again rethink his pathways and reflect on his individual abilities and structural possibilities. He opted to take it a bit more slowly and forge new pathways from more familiar elements, such as doing odd jobs in the neighbourhood and building rapport with his neighbours Again, these pathways were not fully charted trajectories, but were more akin to meandering alleyways made out of quick sand, that led one to move slowly, tentatively, stepping and miss-stepping, retreating and advancing, while balancing different aspirations, senses of belonging, self-confidence and feelings of (un)familiarity and despair. For example, Fake gradually was able to give up his aspiration to become a group leader when he saw the benefit of improving his standing in the wider neighbourhood community. Hence, the connections between an individual (sense of) ability of achieving aspirations, fear and familiarity and senses of belonging are crucial to consider from a development perspective. Raised aspirations without attention to the way that individual (sense of) abilities hinge on self-esteem and sense of belonging may backfire and undermine any development intervention with youth that depart from a theory of aspirations. Above all, Fake's story reveals that raising aspirations without addressing structural possibilities and thus also impossibilities may turn out fatal in the most radical meaning of the word. In the end, 
Fake was not killed by a police bullet or an angry crowd of people, but by the state neglect of roads and corrupt traffic police who are easily bribed when vehicles pass speed limits. With so much stacked against them, 'having focus' thus turns out to be a stubborn kind of hope because, as Kingi told me over and over again, "Without hope you are already dead."

\section{Compliance with Ethical Standards}

Conflict of interest The author declares that there is no conflict of interest with regard to this article and the original research conducted by the author.

Open Access This article is licensed under a Creative Commons Attribution 4.0 International License, which permits use, sharing, adaptation, distribution and reproduction in any medium or format, as long as you give appropriate credit to the original author(s) and the source, provide a link to the Creative Commons licence, and indicate if changes were made. The images or other third party material in this article are included in the article's Creative Commons licence, unless indicated otherwise in a credit line to the material. If material is not included in the article's Creative Commons licence and your intended use is not permitted by statutory regulation or exceeds the permitted use, you will need to obtain permission directly from the copyright holder. To view a copy of this licence, visit http://creativecommons.org/licen ses/by/4.0/.

\section{References}

Appadurai, A. 2004. The Capacity to Aspire: Culture and the Terms of Recognition i. In V. Rao, \& M. (Walton, Culture and Public Action (pp. 59-84). Redwoon city: Stanford University Press.

Bernard, T., A.S. Taffesse, and S. Dercon. 2008. Aspirations failure and well-being outcomes in Ethiopia: towards an empirical exploration. Retrieved from https://www.iig.ox.ac.uk/output/presentations/ pdfs/E13-Aspirations-and-WellBeing-Outcomes-in-Ethiopia.pdf

Bhavnani, R., M.G. Findley, and J.H. Kuklinski. 2009. Rumor Dynamics in Ethnic Violence. The Journal of Politics 71 (3): 876-892.

Bracke, S. 2016. Is the Subaltern Resilient? Notes on Agency and Neoliberal Subjects. Cultural Studies 30 (5): 839-855.

Brotherton, D.C. 2019. Studying the Gang through Critical Ethnography . Retrieved from CUNY Academic Works: academicworks.cuny.edu/gc_pubs/522

Butler, J. 1997. The Psychic Life of Power: Theories in Subjection. Redwood City: Stanford University Press.

Camfield, J., and L. Copestake. 2010. Measuring Multidimensional Aspiration Gaps: A Means to Understanding Cultural Aspects of Poverty. Development Policy Review 28 (5): 617-633.

Clammer, J. 2012. Culture, Development and Social Theory: Towards an Integrated Social Development. London: Zed books.

Davids, T., and K. Willemse. 2014. Embodied Engagements: Feminist Ethnography at the Crossing of Knowledge Production and Representation. An introduction. Women's Studies International Forum 43: $1-4$.

Frye, M. 2012. Bright Futures in Malawi's New Dawn: Educational Aspirations as Assertions of Identity. AJS 117 (6): 1565-1624.

Foti, A. 2017. General theory of the precariat: The great recession, revolution, reaction. Theory on Demand\#25 . Retrieved from networkcultures.org: https://networkcultures.org/blog/publication/ general-theory-of-the-precariat/

Githinji, P. 2006. Bazes and Their Shibboleths: Variation and Sheng Speakers' Identity in Nairobi. Lexical Nordic Journal of African Studies 15 (4): 443-472.

Githiora, C. 2018. Sheng: Rise of a Kenyan Swahili Vernacular. Woodbridge, Suffolk: Boydell \& Brewer. 
Holloway, S., L. Holt, and S. Mills. 2019. Questions of Agency: Capacity, Subjectivity, Spatiality and Temporality. Progress in Human Geography 43 (3): 458-477.

Huijsmans, R., N. Ansell, and P. Froerer. 2021. Editorial Introduction: Development and the Social Production of Aspirations in Young Lives. European Journal of Development Research, 33(1).

Jones, P., W. Kimari, and K. Ramakrishnan. 2017. Only the People can Defend This Struggle: The Politics of the Everyday, Extrajudicial Executions and Civil Society in Mathare, Kenya. Review of African Political Economy 44 (154): 1-18.

Kiama, P. 2017. They Deserve to Die. The Increasingly Accepted Justification for Extrajudicial Killings. The Elephant, 4 May.

Majors, R., and J.M. Billson. 1993. Cool Pose: The Dilemmas of Black Manhood in America. New York: Lexington Books.

Mills, S. 2006. Discourse. New York: Routledge.

MSJC. 2017. A Participatory Actions Research Report Against the Normalization of Extrajudicial Executions in Mathare. Nairobi: MSJC.

Musya, J.K., F. Matanga, and M. Amutabi. 2017. Effect of Political Mobilization on Political Violence in Nairobi County, Kenya: Focus on Mathare and Kibra Informal Settlements. ASJ: International Journal of Management Sciences (IJMS) 1 (1): 01-07.

Ortner, S.B. 2006. Anthropology and Social Theory: Culture, Power, and the Acting Subject. Durham: Duke University Press.

Osse, A. 2016. Police Reform in Kenya: A Process of "Meddling Through." Policing and Society. 18 (1): $7-17$.

Patterson, O. 1982. Slavery and Social Death. Cambridge, MA.: Harvard University Press.

Ray, D. 2006. Aspirations, Poverty and Economic Change. In Understanding Poverty, ed. A.V. Banerjee, R. Bénabou, and D. Mookherjee, 409-421. Oxford: Oxford University Press.

Rodan, L., and R. Huijsmans. 2021. "Our Generation...": Aspiration, Desire, and Generation as Discourse Among Highly Educated, Portuguese, Post-austerity Migrants in London. European Journal of Development Research. https://doi.org/10.1057/s41287-020-00299-4.

Skeggs, B. 2004. Class, Self, Culture. London: Routledge.

Spencer, S., C. Logel, and P. Davies. 2016. Stereotype Threat. The Annual Review of Psychology 67: 415-437.

Van Stapele, N. 2016. 'We are not Kenyans': Extra-Judicial Killings, Manhood and Citizenship in Mathare, a Nairobi Ghetto. Conflict, Security \& Development 16 (4): 301-325.

Van Stapele, N. (forthcoming). Providing to Belong-Masculinities, Hustling and Economic Uncertainty in Nairobi 'Ghettos'. Africa.

Vigh, H. 2006. Navigating Terrains of War: Youth and Soldiering in Guinea-Bissau. New York: Berghahn Books.

Vigh, H. (2009). Motion Squared. Landscapes, seascapes and a second look at the concept of social navigation. ASSR Seminar, University of Amsterdam. Amsterdam.

Vigh, H. 2009. Motion Squared: A Second Look at the Concept of Social Navigation. Anthropological Theory 9: 419-438.

Weidner, J. 2009. Governmentality, Capitalism, and Subjectivity. Global Society 23 (4): 387-411.

Whyte, S.R. 1997. Questioning Misfortune: The Pragmatics of Uncertainty in Eastern Uganda. Cambridge: Cambridge University Press.

Willemse, K. 2007. One Foot in Heaven: Narratives on Gender and Islam in Darfur, West-Sudan. Leiden: Brill.

Publisher's Note Springer Nature remains neutral with regard to jurisdictional claims in published maps and institutional affiliations. 